|| ISSN(online): 2589-8698 || ISSN(print): 2589-868X ||

International Journal of Medical and Biomedical Studies Available Online at www.ijmbs.info

NLM (National Library of Medicine ID: 101738825)

Index Copernicus Value 2020: 79.44

\title{
BIOCHEMICAL AND CLINICAL CHARACTERIZATION OF IODINE DEFICIENCY DISORDERS IN CENTRAL
} INDIA

Nagendra Kishanprasad Yembarwar', Sanjay G Guddetwar²

${ }^{1}$ Junior Scientific Officer, Dept. of Nephrology, Seth G S Medical College and KEM Hospital, Parel, Mumbai

${ }^{2}$ PhD Scholar Medical Biochemistry, Dept. of Biochemistry, MGM Medical College, Aurangabad

Article Info: Received 01 January 22; Accepted 11 February 2022

DOI: https://doi.org/10.32553/ijmbs.v6i2.2430

Corresponding author: Sanjay G Guddetwar

Conflict of interest: No conflict of interest.

\section{Abstract}

Background: Iodine (I) is a trace element that is required by both humans and animals. It can be found in a variety of chemical forms, including iodine, iodide (I), and iodate (IO3). It is widely distributed across the earth's ecology, with a concentration in the oceans. Iodine entered the natural cycle from the ocean, the atmosphere, and rainfall, as well as from rainfall into streams and rivers. Iodine is absorbed as iodide in human nutrition. Iodine is a necessary micronutrient and a component of thyroid hormones. Fish and seafood have a high iodine level. The amount of iodine in soil and drinking water varies depending on where it comes from. Iodine shortage produces a variety of negative health consequences, which are referred to as iodine deficiency illnesses (IDD). These conditions are caused by a lack of iodine, which causes insufficient thyroid hormone production.

Aim: The aim of this study is to characterize the iodine deficiency disorder by biochemical and clinical assessment and to correlate the iodine status with thyroid disorder(s) in adults.

Material and Method: The samples for this investigation were taken from patients at the Department of Endocrine Surgery. This study comprised a total of 100 hundred goiter patients, who had their urinary iodine excretion and thyroid hormone levels examined. For all goiter patients, the grading of goitre was established using the WHO/UNICEF/ICCIDD approved criteria. TSH, Free T4, Free T3 by using ELISA Method using commercial kits. Anti-microsomal antibody (AMA) or Thyroperoxidase antibody (TPO-Ab) by using ELISA Method using commercial kits. Anti-thyroglobulin antibody (ATG) estimated by using ELISA Method using commercial kits.

Results: The data for each group were presented as Median and inter quarter range (IQR) The median and IQR of Urinary iodine excretion of the hypothyroid, hyperthyroid and Euthyroid goiter subjects were respectively and there was significant difference in the median urinary iodine excretion. The median and IQR of Urinary iodine excretion of the thyroiditis, thyrotoxicosis, cancer of thyroid and benign goiter respectively and there was significant difference in the median urinary iodine excretion.

Conclusion: For ages, endemic goitre and cretinism have been recognised as public health issues, and iodine deficiency is thought to be the leading cause of preventable mental retardation. Most countries now include iodine deficiency control as part of their national nutrition policies. To eliminate iodine deficiency, several therapies with high efficacy have been employed, including iodized oil capsules (IOC) and universal salt iodisation (USI). Although some progress has been made, efforts to eliminate this devastating health problem must be hastened. Not only should iodine deficiency be monitored, but so should excessive iodine intake, as this is a problem in various areas, including the camps.

Keywords: IDD, Goitre, TSH, IOC, USI, ATG, AMA, T4, T3.

\section{Introduction}

Iodine is an essential element in the production of thyroid hormones and is essential for the normal functioning of various organs including thyroid gland and breast cancer. It is also important for the emotional development of the child and the child. The main source of iodine is food from foods such as seafood and plants grown in adequate iodine areas. Iodine-rich foods; diary product and bread are also good sources. ${ }^{1}$

Iodine deficiency leads to iodine deficiency problems (IDD), clinical manifestations and low iodine deficiency, collectively defined by the term Iodine deficiency disorders
(IDD) which affects all ages and is a major public health problem worldwide. Lack of iodine damages a person's health in many ways, most importantly by disrupting normal brain growth. Iodine Deficiency Disorders (IDD) include many diseases, including goiter, hypothyroidism, cretinism, impaired growth, hearing loss, childbirth, miscarriage, income loss, and brain damage. Some of the effects of iodine deficiency are irreversible, but all can be completely prevented by easily accessible iodine injection techniques. Iodine Deficiency Disorders are the most common cause of preventable mental illness and mental retardation affecting 118 countries around the world. Iodine deficiency is a major 
health problem in India. In India 275 provinces of 25 provinces and 4 union areas in India have identified 235 regions as epidemics of Iodine Deficiency Disorders (IDDs). However, only $70 \%$ of the world's edible salt is iodized because there is no effective regulation of the country's thyroid health. Urinary iodine balance plays an important role in controlling iodine deficiency disorders. ${ }^{2}$

IDD affects all stages of a person's life and covers a wide range of conditions including Goitre, Cretinism, and Dwarfism, mental retardation, muscle disorders, spontaneous abortions and Reproduction. This in turn leads to serious illnesses and declining livelihoods and declining economic productivity. India is one of the most dangerous areas in IDD where 167 million people are at risk, 54 million people have Goitre, 6.6 million have minor neurological disabilities and 2.2 million have cretinism. ${ }^{3}$ Thyroid hormones are very important and have a variety of functions. They work on almost every cell in the body to alter genetic makeup: too little or too little production of these hormones has serious consequences. Disorders related to thyroid hormone replacement are common and affect about $5 \%$ of women and $0.5 \%$ of men. Normal levels of thyroid hormones are required for Neuronal migration and Myelination of the baby's brain and Iodine deficiency irregularly impairs brain development. $^{4}$

During the last few decades, the global effort to avoid iodine deficiency illnesses with iodine supplementation, such as universal salt iodization, has made significant success. Adults who are not pregnant or lactating should consume 150 $\mathrm{g}$ of iodine each day. Iodine ingestion or exposure above this level is usually well tolerated. The chance of developing iodine-induced thyroid dysfunction may be enhanced in certain vulnerable individuals, such as those with preexisting thyroid disease, the elderly, foetuses and neonates, or those with other risk factors. Hypothyroidism or hyperthyroidism caused by supraphysiologic iodine exposure might be asymptomatic or overt, and the source of extra iodine isn't always obvious. ${ }^{5}$

Since iodine deficiency disorders involving the thyroid gland are commonly encountered in the population, we have undertaken this study. In this study we have proposed to investigate the association of iodine status among the population with thyroid glandular dysfunctions.

\section{Material and Methods}

The samples for this investigation were taken from patients at the Department of Endocrine Surgery. This study comprised a total of 100 hundred goiter patients, who had their urinary iodine excretion and thyroid hormone levels examined. For all goiter patients, the grading of goitre was established using the WHO/UNICEF/ICCIDD approved criteria. TSH, Free T4, Free T3 by using ELISA Method using commercial kits. Anti-microsomal antibody (AMA) or Thyroperoxidase antibody (TPO-Ab) by using ELISA
Method using commercial kits. Anti-thyroglobulin antibody (ATG) estimated by using ELISA Method using commercial kits.

\section{Patients}

The following groups of patients were taken up for the study:

* Group I: 100 adult patients with thyroid dysfunction who were admitted to the Endocrine Surgery Department.

\section{Controls:}

Age and sex matched controls were included for each group

* Group II - 100 healthy volunteers with normal thyroid function

\section{Inclusion criteria:}

* Patient with disorders of thyroid such as goiter (hyperthyroidism or hypothyroidism), thyroiditis, cancer of thyroid.

\section{Exclusion criteria}

* Patient with thyroid dysfunction having other illness such as Diabetic mellitus or any other associated illnesses.

* Children with thyroid dysfunction

* Pregnant women with and without thyroid dysfunction.

\section{Chemicals}

All chemicals and other analytical reagents were purchased from Ranbaxy laboratories Ltd, India, Scientific Fisher chemical Ltd, India, Sigma Aldrich, India and Invitrogen, India.

\section{Sample Collection}

Blood samples were collected in two plain red-top venepuncture tubes. The tubes were centrifuged at $2000 \mathrm{rpm}$ for 15 minutes for Thyroid function test estimation and for other investigations too. Along with blood samples spot urine samples was also collected in sterile plastic containers.

\section{Methods:}

The following Thyroid function tests were performed:

- TSH Free T4, Free T3 by using ELISA Method using commercial kits

- Anti-microsomal antibody (AMA) or Thyroperoxidase antibody (TPO-Ab) by using ELISA Method using commercial kits.

- Anti-thyroglobulin antibody (ATG) estimated by using ELISA Method using commercial kits.

\section{RESULT:}

The data for each group were presented as Median and inter quarter range (IQR) The median and IQR of Urinary iodine excretion of the hypothyroid, hyperthyroid and Euthyroid 
goiter subjects were respectively and there was significant difference in the median urinary iodine excretion. The median and IQR of Urinary iodine excretion of the thyroiditis, thyrotoxicosis, cancer of thyroid and benign goiter respectively and there was significant difference in the median urinary iodine excretion.

Table 1: Case control thyroid profile for adult group

\begin{tabular}{|l|l|l|}
\hline Parameters (Units) & $\begin{array}{l}\text { Case group } \\
\mathbf{n = 1 0 0}\end{array}$ & $\begin{array}{l}\text { Control group } \\
\mathbf{n = 1 0 0}\end{array}$ \\
\hline Age (Years) & $40.77 \pm 11.22$ & $26.55 \pm 4.09$ \\
\hline $\begin{array}{l}\text { UIE ( } \mu \mathrm{g} / \mathrm{L}) \\
\text { Ref. (100-200) }\end{array}$ & $270.33 \pm 120.44$ & $150.21 \pm 35.66$ \\
\hline $\begin{array}{l}\text { TSH (micro IU/ml) } \\
\text { Ref (0.35-5.0) }\end{array}$ & $18.52 \pm 32.65$ & $1.47 \pm 1.15$ \\
\hline $\begin{array}{l}\text { FT4 (ng/dl) } \\
\text { Ref }(0.8-2.0)\end{array}$ & $1.81 \pm 1.68$ & $1.55 \pm 0.98$ \\
\hline $\begin{array}{l}\text { FT3 (pg/dl) } \\
\text { Ref. (2.0-4.4) }\end{array}$ & $2.34 \pm 1.79$ & $1.88 \pm 0.44$ \\
\hline $\begin{array}{l}\text { AMA (IU/ml) } \\
\text { Ref. }(<35)\end{array}$ & $40.11 \pm 1.92$ & $31.67 \pm 0.69$ \\
\hline $\begin{array}{l}\text { ATG (IU/ml) } \\
\text { Ref. }(<110)\end{array}$ & $115.43 \pm 4.88$ & $93.58 \pm 2.29$ \\
\hline
\end{tabular}

Table 2: Classification based on Thyroid status of thyroid gland

\begin{tabular}{|l|l|l|l|}
\hline Parameters (Units) & $\begin{array}{l}\text { Hypothyroid } \\
\mathbf{n}=\mathbf{3 0} \text { median }\end{array}$ & $\begin{array}{l}\text { Hyperthyroid } \\
\mathbf{n = 3 5} \text { median }\end{array}$ & $\begin{array}{l}\text { Euthyroid goiter } \\
\mathbf{n}=\mathbf{3 0} \text { median }\end{array}$ \\
\hline $\begin{array}{l}\text { UIE }(\mu \mathrm{g} / \mathrm{L}) \\
\text { Ref. }(100-200)\end{array}$ & $245(160-295)$ & $315(210-350)$ & $230(140-320)$ \\
\hline $\begin{array}{l}\text { TSH }(\mathrm{micro} \text { IU/ml) } \\
\text { Ref }(0.35-5.0)\end{array}$ & $25(6.84-72)$ & $0.03(0.03-0.010)$ & $1.98(1.10-2.93)$ \\
\hline $\begin{array}{l}\text { FT4 }(\mathrm{ng} / \mathrm{dl}) \\
\text { Ref }(0.8-2.0)\end{array}$ & $0.88(0.40-0.94)$ & $4.95(2.69-7.43)$ & $1.75(1.35-1.95)$ \\
\hline $\begin{array}{l}\text { FT3 }(\mathrm{pg} / \mathrm{dl}) \\
\text { Ref. }(2.0-4.4)\end{array}$ & $1.53(0.94-1.89)$ & $8.66(6.08-11.37)$ & $3.33(2.68-3.44)$ \\
\hline $\begin{array}{l}\text { AMA }(\mathrm{IU} / \mathrm{ml}) \\
\text { Ref. }(<35)\end{array}$ & $280(250-360)$ & $255(180-330)$ & $35(30-45)$ \\
\hline $\begin{array}{l}\text { ATG }(\mathrm{IU} / \mathrm{ml}) \\
\text { Ref. }(<110)\end{array}$ & $370(280-520)$ & $465(370-530)$ & $135(90-200)$ \\
\hline
\end{tabular}

Data were presented as Median and inter quarter range (IQR).

The median and IQR of Urinary iodine excretion of the hypothyroid, hyperthyroid and Euthyroid goiter subjects was was significant difference in the thyroid stimulating hormones, free thyroxine, free triiodothyronine. The median and IQR of Urinary iodine excretion of the hypothyroid, hyperthyroid and Euthyroid goiter subjects was significant difference in the Anti-microsomal antibody (AMA) or Anti Thyroid peroxidase antibody. The median and IQR of Urinary iodine excretion of the hypothyroid, hyperthyroid and Euthyroid goiter was significant difference in the Antithyroglobulin antibody

\section{Discussion}

Iodine is a component of thyroid hormones, which play a role in human mental and physical development as well as maintaining homeostasis. Reduced iodine consumption can lead to a variety of iodine shortage illnesses (IDD). Iodine deficiency affects around two billion people globally and is the most common avoidable cause of mental impairment. ${ }^{6}$

The results of the present study showed good agreement among the different thyroid hormone profile, and excess urinary iodine excretion. Urinary iodine was positively correlated with thyroxin, Triiodothyronine, anti-microsomal antibody, and anti-thyroglobulin antibody. Among the adult patients with different thyroid disorders, there was a significant positive correlation between urinary iodine excretions and thyroid stimulating hormone, thyroxine, triiodothyronine levels. Also, a significant positive correlation between urinary iodine to anti-microsomal antibody and anti-thyroglobulin antibody were found. Our results suggest 
a possible link between excess urinary iodine and thyroid disorders like thyroiditis, thyrotoxicosis and thyroid cancer. ${ }^{7}$

Iodine's influence on thyroid function is highly varied and dependent on thyroid gland health. Dunn. ${ }^{8}$ Tajiri et al. ${ }^{9}$ and Mizukami et al. ${ }^{10}$ discovered evidence of a reversible kind of hypothyroidism susceptible to iodine limitation, with very slight changes in lymphocytic thyroiditis. This shows that this type of hypothyroidism should be given special attention, as iodine restriction alone may be enough to restore thyroid function.

Low iodine, thiocyanate exposure, and thyroid autoimmunity all have a role in goitre formation, according to a study conducted across the country by R. K. Marwaha et al after salt iodination. ${ }^{11}$ This study also found that goitrous people are more likely to develop thyroid disease with functional abnormalities.

Excess consumption has been linked to iodine induced hyperthyroidism (IIH) and autoimmune thyroiditis, owing to the stimulation of thyroid follicular cell growth, which increases the risk of mutations. ${ }^{12}$ Almost all iodine supplementation regimens have been linked to the development of IIH. ${ }^{13}$

To assess the impact of the USI program, as well as to ensure sustainability, the World Health Organization has recommended urine iodine measurement as a standard method of assessing dietary iodine intake by the public. The release of iodine in the urine is a good indicator of iodine intake and, therefore, is a preferred indicator for assessing the level of iodine deficiency and its correction.

Even though the USI program has almost eliminated iodine deficiency in goiter areas, the spread of goiter has not been eliminated. In fact, the emergence of thyroid-related disorders has shown a steady increase in trends over the past decade. Despite eating iodine-containing salts, increased thyroid disorders have led us to investigate iodine status among these patients and to be associated with thyroid function. ${ }^{2}$

\section{Conclusion:}

For ages, endemic goitre and cretinism have been recognised as public health issues, and iodine deficiency is thought to be the leading cause of preventable mental retardation. Most countries now include iodine deficiency control as part of their national nutrition policies. To eliminate iodine deficiency, several therapies with high efficacy have been employed, including iodized oil capsules (IOC) and universal salt iodisation (USI). Although some progress has been made, efforts to eliminate this devastating health problem must be hastened. Not only should iodine deficiency be monitored, but so should excessive iodine intake, as this is a problem in various areas, including the camps.

\section{References:}

1. Hetzel BS. Iodine deficiency disorders (IDD) and their eradication. Lancet. 1983 Nov 12;2(8359):1126-9.

2. Sohal KS, Sharma TD, Kapil U, Tandon M. Current status of prevalence of goitre and iodine content of salt consumed in District Solan, Himachal Pradesh. Indian Pediatr. 1999 Dec;36(12):1253-6.

3. WHO Secretariat, Andersson M, de Benoist B, Delange F, Zupan J. Prevention and control of iodine deficiency in pregnant and lactating women and in children less than 2-years-old: conclusions and recommendations of the Technical Consultation. Public Health Nutr. 2007 Dec;10(12A):1606-11.

4. Kapil U, Singh P, Dwivedi SN, Pathak P. Profile of iodine content of salt and urinary iodine excretion levels in selected districts of Tamil Nadu. Indian J Pediatr. 2004 Sep;71(9):785-7.

5. Semba, R. D. \& Delange, F. Iodine Deficiency Disorders. In: R. D. Semba \& M. W. Bloem (Eds.). 2nd ed. Totowa: Humana Press Inc.; 2008. 507-529

6. WHO/UNICEF/ICCIDD Consultation. Indicators for Assessing Iodine Deficiency Disorders and Their Cont rol Programmes. Geneva: WHO; 1992.

7. Lee K, Bradley R, Dwyer J, Lee SL. Too Much versus Too Little: the Implications of Current Iodine Intake in the United States. Nutr Rev. 1999 Jun 1;57(6):177-81.

8. Dunn JT. What's happening to our iodine? J Clin Endocrinol Metab. 1998 Oct;83(10):3398-400.

9. Tajiri J, Higashi K, Morita M, Umeda T, Sato T. Studies of Hypothyroidism in Patients with High Iodine Intake. J Clin Endocrinol Metab. 1986 Aug 1;63(2):412-7.

10. Mizukami Y, Michigishi T, Nonomura A, Hashimoto $\mathrm{T}$, Tonami N, Matsubara $\mathrm{F}$, et al. Iodine-induced hypothyroidism: a clinical and histological study of 28 patients. J Clin Endocrinol Metab. 1993 Feb $1 ; 76(2): 466-71$.

11. Marwaha RK, Tandon N, Gupta N, Karak AK, Verma K, Kochupillai N. Residual goitre in the postiodization phase: iodine status, thiocyanate exposure and autoimmunity. Clin Endocrinol (Oxf). 2003 Dec;59(6):672-81.

12. M H Jonckheer BV. Further characterization of iodideinduced hyperthyroidism based on the direct measurement of intrathyroidal iodine stores. Nucl Med Commun. 1992;13(2):114-8.

13. Stanbury J b., Ermans A e., Bourdoux P, Todd C, Oken E, Tonglet R, et al. Iodine -Induced Hyperthyroidism: Occurrence and Epidemiology. Thyroid. 1998 Jan $1 ; 8(1): 83-100$ 